\title{
Bacterial and fungal profile, drug resistance pattern and associated factors of isolates recovered from blood samples of patients referred to Ethiopian Public Health Institute: cross-sectional study
}

Etsehiwot Adamu Tsegaye ${ }^{1 *}$, Dejenie Shiferaw Teklu' ${ }^{1}$, Zelalem Tazu Bonger ${ }^{3}$, Abebe Aseffa Negeri ${ }^{1}$, Tesfaye Legesse Bedada ${ }^{1}$ and Adane Bitew ${ }^{2}$

\begin{abstract}
Background: Blood stream infections are serious infections that usually induce prolongation of hospital stay, morbidity and mortality in several countries including Ethiopia. The aim of this study was to determine bacterial and fungal profile, their drug resistance patterns, and risk factors associated with blood stream infections.

Methods: A cross sectional study design was conducted from February 23 to June 23, 2020 at Ethiopian public health. A structured questionnaire was used to collect data on socio-demographic factors and clinical conditions. Blood specimens were analyzed using standard microbiological techniques. Antimicrobial susceptibility tests were performed using Kirby-Bauer disc diffusion technique and Vitek compact 2. Simple and multiple logistic regressions were used to assess the potential risk factors.

Results: A total of 175 pathogens isolated from 346 blood specimens. Of these, 60\% Gram-negative bacteria, 30.86\% Gram-positive bacteria and 9.14\% fungal isolates were identified. Burkholderia cepacia and Coagulase negative staphylococcus were the predominant pathogen among Gram-negative and Gram-positive bacteria respectively. Among fungus, Candida krusei (56.25\%) was the most predominant isolate. The highest proportions of antibacterial resistance were observed among $3 \mathrm{rd}$ generation cephalosporin and penicillin. Most fungal isolates expressed resistance to fluconazole. Sex $(P=0.007)$, age $(P<0.001)$ and use of invasive medical devices $(P=0.003)$ were identified as risk factors for bacterial blood stream infections.

Conclusion: The study showed high prevalence of blood stream infection was due to B. cepacia and non-C. albicans spp. This finding alarming ongoing investigation of blood stream infection is important for recognizing future potential preventive strategies including environmental hygiene and management of comorbid medical diseases to reduce the problem.
\end{abstract}

Keywords: Blood stream infections, Bacterial and fungal profile, Antimicrobial resistance pattern, Risk factor, Ethiopia

*Correspondence: etseadamu@gmail.com

${ }^{1}$ National Clinical Bacteriology and Mycology Case Team, Ethiopian

Public Health Institute, Addis Ababa, Ethiopia

Full list of author information is available at the end of the article

\section{Background}

Blood stream infections (BSIs) are the major public health problems that are responsible for the cause of selflimited infection to death worldwide [1]. These infections 
can be intravascular or extravascular. Most bacterial species and many fungal species have been associated with extravascular bloodstream infections [2].

According to the global report of the World Health Organization, sepsis affected 49 million individuals and related to approximately 11 million potentially unavoidable deaths worldwide [3]. In the United States, there are about 200,000 cases of bacteria and fungi occurred annually, with mortality rates ranging from 20 to $50 \%$ [4].

Several recent studies have shown that the conditions that predispose an individual to BSIs vary with age, gender, and underlying diseases. More than half of all cases of global sepsis occurred among adolescents and children [5]. There is around 53\% mortality rate among children in sub-Saharan Africa, including Ethiopia [6]. The elderly population is exposed to BSIs associated with the use of a variety of medical procedures [7].

Diabetes mellitus, renal failure requiring dialysis, widespread use of broad-spectrum antibiotics, hepatic cirrhosis, gender, age, and malignancy are the main risk factors that lead to BSIs $[8,9]$. Other factors that enhance BSIs among hospitalized patients include decreased immunity, increased variety of medical procedures and the transmission of drug-resistant bacteria among crowded hospital populations [10].

As many studies highlighted, bacteria are the primary causative agents of BSIs [11-13]. However, fungal pathogens began to be recognized as important causes of disease related to increasing numbers of immunocompromised patients and nosocomial infections. Among them, $65 \%$ of the BSIs cases are induced by Candida which is responsible for raising the number of mortality rate by $38 \%$ and extending hospital stays of 30 days [14].

A large variety of organisms can cause bloodstream infections, which vary by institution and geographic distribution [15]. Coagulase-negative staphylococcus, Staphylococcus aureus and Enterococcus spp. are the most common BSIs causing Gram-positive bacterial pathogens. Klebsiella pneumoniae, Escherichia coli, Pseudomonas spp. and Acinetobacter baumannii are also the commonest among Gram-negative organisms. Candida glabrata, C. parapsilosis, C. tropicalis, and C. krusei also become frequent from fungal species [16].

In Ethiopia, systemic review done in bloodstream infections showed that the proportion of blood stream infections ranged from (12.84-18.15\%). The common pathogens isolated from bacterial infected patients were S. aureus and E. coli [17]. However, it is difficult to generalize these findings to all levels of health care facilities in Ethiopia.

Blood culture remains the gold standard for bacterial and fungal detection from BSIs. Irrational use of drugs has led to an increase of multidrug-resistant organisms and thus worsened the condition. Therefore, preliminary results of Gram staining, final identification and AST results are essential for providing safe, effective, and efficient care of patients $[16,18]$.

The burden of blood streams infections due to antifungal resistance and associated risk factors in Ethiopia remains poorly reported. Although previous studies have been performed in the same laboratory, they have been limited to bacterial causative agents and showed the past trends of the pathogen [19]. Therefore, this study was designed to determine the current status of organisms causing bloodstream infections, their antimicrobialresistant patterns and associated factors related to the infections among patients referred to Ethiopian Public Health, National clinical bacteriology, and mycology reference laboratory.

\section{Methods}

\section{Study design, period and setting}

An institutional based cross-sectional study was conducted on blood specimens from February 23 to June 23, 2020. All methods were performed in accordance with the relevant guidelines and regulations. The specimens were referred from all health care facilities in the chain of referral systems of the Department of Clinical Bacteriology and Mycology laboratory. The laboratory is the national referral laboratory in the country responsible for providing high-level diagnostic laboratory testing services for patients and specimens referred from all regional and federal health facilities. It was accredited by the Ethiopian National Accreditation office. In addition, the laboratory conducts research, capacity of regional and federal laboratory and participates in AMR surveillance. The health care facilities involved during the study period were Ras desta Hospital, Abet Hospital, St Peter Hospital, Federal Police Hospital, Yekatit Hospital, Minilik Hospital, Ring Road Hospital, Girum Hospital and Armed Force Hospital.

\section{Sample collection and processing}

Aseptic precautions were followed to collect a total of 346 blood samples from suspected patients. Blood culture bottle was prepared with $50 \mathrm{ml}$ and $25 \mathrm{ml}$ tryptic soy broth containing $0.025 \%$ of sodium polyanethol sulphonate (SPS) as anticoagulant for adult and for children respectively. Two bottle of blood culture were used with $10 \mathrm{ml}$ volume for adult, $5 \mathrm{ml}$ for children and $2 \mathrm{ml}$ for neonates.

A blind subculture was done after overnight incubation to appropriate solid culture media. Bottles that showed turbidity was subjected to Gram staining followed by sub-cultured onto blood agar plates (Oxoid Ltd, UK), chocolate agar plates (Oxoid Ltd, UK) and MacConkey 
agar plates (Oxoid Ltd, UK). Blood agar and chocolate agar plates were incubated in $5 \% \mathrm{CO}_{2}$ for $24-72 \mathrm{~h}$. MacConkey agar plates were placed aerobically for $24 \mathrm{~h}$. Two plates of sabouraud dextrose agar plates were inoculated and incubated at $37{ }^{\circ} \mathrm{C}$ and $25^{\circ} \mathrm{C}$. Identification of bacterial isolates was carried out according to the standard bacteriological technique. A terminal sub culturing was done on chocolate agar for bottles that did not show visible growth within 7 days before being reported as negative. Species identification of some bacteria and yeasts were determined by the automated Vitek 2 compact machine (bioMérieux, France) using GN and YS 07 cards respectively.

\section{Antibiotic susceptibility testing}

Antibiotic susceptibility testing was conducted on Muller-Hinton agar by Kirby-Bauer Disk diffusion method according to Clinical Laboratory Standard Institute (CLSI) guidelines 2021 [20]. Antimicrobial agents used for testing bacterial isolates were Penicillin (MIC), oxacillin $(30 \mu \mathrm{g})$, gentamycin $(10 \mu \mathrm{g})$, vancomycin $(\mathrm{MIC})$, vancomycin $(30 \mu \mathrm{g})$, chloramphenicol $(30 \mu \mathrm{g})$, cefotaxime (30 $\mu \mathrm{g})$, ceftazidime $(30 \mu \mathrm{g})$, meropenem $(10 \mu \mathrm{g})$, trimethoprim-sulphamethoxazole $(1.25 / 23.75 \mu \mathrm{g})$, amoxicillin-clavulanic acid $(20 / 10 \mu \mathrm{g})$, piperacillin-tazobactam $(100 / 10 \mu \mathrm{g})$, ceftriaxone $(30 \mu \mathrm{g})$, cefepime $(30 \mu \mathrm{g})$, amikacin $(30 \mu \mathrm{g})$ and ciprofloxacin $(5 \mu \mathrm{g})$. These antimicrobial agents were selected based on current availability and frequently prescribed for the management of bacterial infections in Ethiopia [21].

Anti-fungal susceptibility tests for Amphotericin B $(10 \mu \mathrm{g})$, caspofungin $(5 \mu \mathrm{g})$, flycytosine, fluconazole (25 $\mu \mathrm{g})$, Micafungin and Voriconazole $(1 \mu \mathrm{g})$ were done for all yeasts isolates by automated VITEK 2 compact system (bioMérieux, France) using AST-YSO1 cards. The quality controls of the drugs were checked for its performance by using E. coli (ATCC-25922), S. aureus (ATCC25923), P. aeruginosa (ATCC-27853) and C. albicans (ATCC-10231).

\section{Data collection}

Socio-demographic data and clinical status of patients were collected through a standard questioner.

\section{Statistical analysis}

Data were collected analyzed using WHONET and R software programs. Simple and multiple logistic regression analyses were used to assess the possible risk factors of bloodstream infections. Multiple logistic regression models were done only for variables with P-value less than 0.25 . P-value $<0.05$ was considered statistically significant for all cases.

\section{Ethical issues}

The study was conducted after obtaining ethical clearance and approval from the department of medical laboratory sciences, Addis Ababa University who had ethics committee to approve the study on humans (DREERC/452/19/MLS). An official permission letter was obtained from Addis Ababa Public health Research and Emergency Directorate for all referral hospitals for sample collection. Data collection was started after written informed consent/ascent was obtained from the study participants. Informed consent was also obtained from parent/guardian of study participants below 16 years of age.

\section{Results}

Socio-demographic characteristics of patients

The study involved a total of 346 patients with suspected BSIs. Out of them, 126 (36.42\%) were female. The majority of the study participants were infants $186(53.76 \%)$ and few participants 16 (4.62\%) were elderly age groups (Table 1). More than half participants in the study were from NICU (51.16\%) (Fig. 1).

\section{Clinical condition of study participants}

Invasive medical devices such as catheter usage were observed in 178 (54.60\%) study participants during their hospital stay. Patient histories revealed that they had different underlying clinical conditions. Most study participants 169 (48.84\%) developed sepsis. One hundred twenty-five (36.13\%) of the patients had a previous history of hospital admission related to similar symptoms with the current infections or with other health problems. Other comorbidities were also observed in study participants. These included: history of surgery 70 (20.23\%), prolonged rupture of membrane 15 (4.34\%), malignancy 20 (5.78\%), diabetic mellitus 28 (8.09\%), hepatic problem 29 (8.38\%), hemodialysis $12(3.47 \%)$ and

Table 1 Demographic characteristics of study participants referred to Clinical Bacteriology and Mycology laboratory from February 23 to June 23, 2020

\begin{tabular}{llc}
\hline Variables & Category & N (\%) \\
\hline Gender & Female & $126(36.42)$ \\
\multirow{2}{*}{ Age } & Male & $220(63.58)$ \\
& Infant (<1yearr) & $186(53.76)$ \\
& Children (1-12 years) & $27(7.80)$ \\
& Adult (13-64 years) & $117(33.82)$ \\
Place of residence & Elderly (>65 years) & $16(4.62)$ \\
& Outside of Addis Ababa & $211(60.98)$ \\
& Addis Ababa & $135(39.02)$ \\
\hline
\end{tabular}




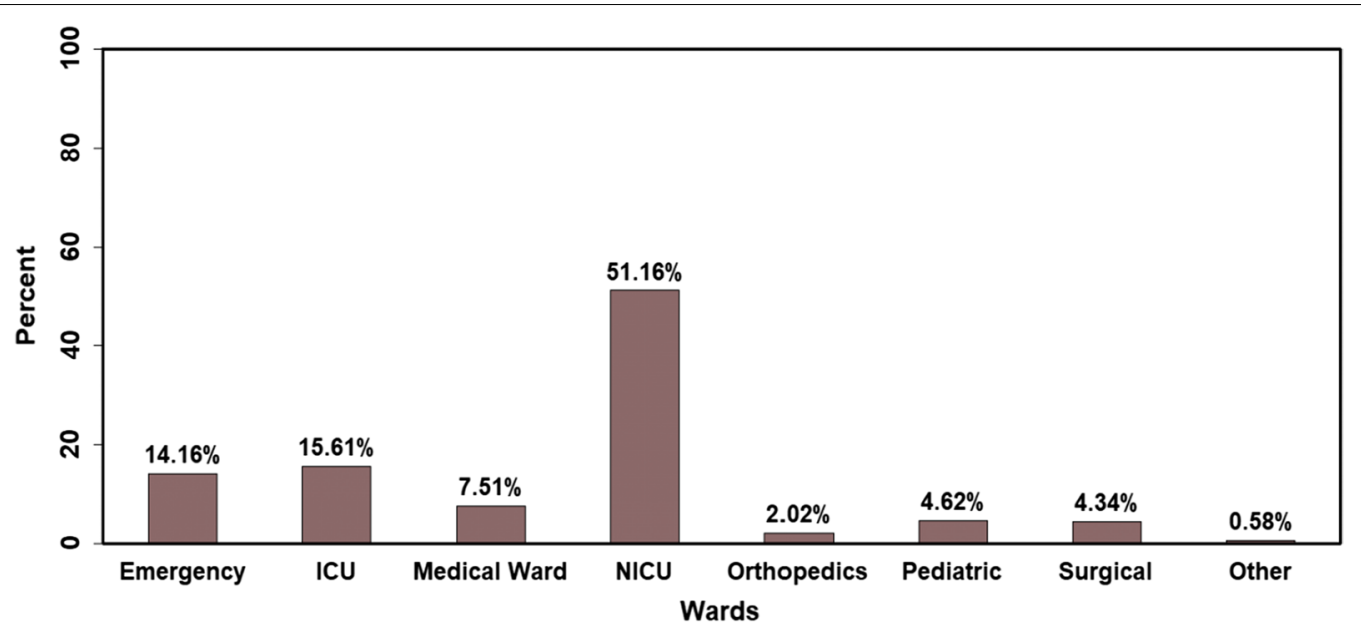

Fig. 1 Distribution of patients with suspected BSIs referred to EPHI, Clinical Bacteriology and Mycology reference laboratory from February 23 to June 23, 2020 according to the hospital wards

32 (9.25\%) had other complications. One patient was with a history of bone marrow transplantation.

The majority of patients $286(82.66 \%)$ were treated with empiric antibiotics prior to blood culture results. Of these, most of the patients $(67.84 \%)$ were treated with a combination of aminoglycoside, Beta-lactam inhibitor and third generation cephalosporins. The rest of the participants $(25.87 \%)$ had taken a combination of carbapnem and glycopeptide. A few patients (6.29\%) were treated with metronidazole as well.

\section{Fungal and bacterial isolates}

Positive growth was observed in 175 (50.58\%) isolates under aerobic cultural environments. The isolates were considered as contaminant when recovered from one bottle and excluded from our results. Only isolates recovered from both bottle were considered as true pathogen and included in analysis. All positive blood samples were detected for a single type of organism. From the recovered isolates 54 (30.86\%) were Gram-positive bacteria, 105 (60\%) were Gram-negative bacteria and 16 (9.14\%) were fungal isolates. Among Gram-positive isolates, Coagulase-negative staphylococcus (74.07\%) was the predominant bacteria followed by Enterococcus spp. (14.81\%). On the other hand, Burkholderia cepacia was the predominant bacteria among Gram-negative bacterial isolates which accounted for (61.90\%). All fungal isolates identified were non-C. albicans spp. The most frequently isolated fungi was C. krusei (56.25\%) (Fig. 2).

\section{Antimicrobial resistance patterns}

The microbial isolates showed varying degrees of resistance to different antibiotics tested. Overall, Gram-positive bacteria exhibited a high degree of resistance to
Penicillin. Methicillin resistance defined as resistance to the antibiotic methicillin and other common antibiotics, such as amoxicillin, oxacillin, and penicillin [22]. MRSA was detected in $89.7 \%$ of Coagulase-negative staphylococcus (Table 2).

Antimicrobial resistance levels of Gram-negative organisms for the most commonly causing BSIs were relatively high. $K$. pneumoneia showed the highest resistance in folate pathway inhibitors (85.7\%), floroquionoles (83.3\%), aminoglycoside $(84.2 \%)$ and thirdgeneration cephalosporins (81\%). From the member of non-enterobacterciae Acintobacter spp. showed extreme resistance to ciprofloxacin (100\%). On the contrary, Pseudomonas spp. was susceptible to most of the antibiotics tested. Multidrug drug resistance was observed in $65 \%$ of Gram-negative bacterial isolates (Table 3).

The antimicrobial susceptibility patterns of Candia species were performed using Vitek compact 2 machine according to the M44 guideline [23]. C. rugosa and C. dubliniensis were resistance to fluconazole (100\%). All Candida isolates were susceptible to voriconazole (Table 4).

\section{Multidrug resistance pattern of bacterial isolates}

Multidrug drug resistance (MDR) is occurs when an organism acquired non-susceptibility to at least one agent in three or more antimicrobial categories [24]. MDR level was $65 \%$ that was only seen among Gramnegative bacterial isolates. Highest MDR was observed in K. pneumoniae and Acinitobacter spp. The Pseudomonas spp. and B. cepacia found to be non MDR for the antibiotics tested (Table 5). 


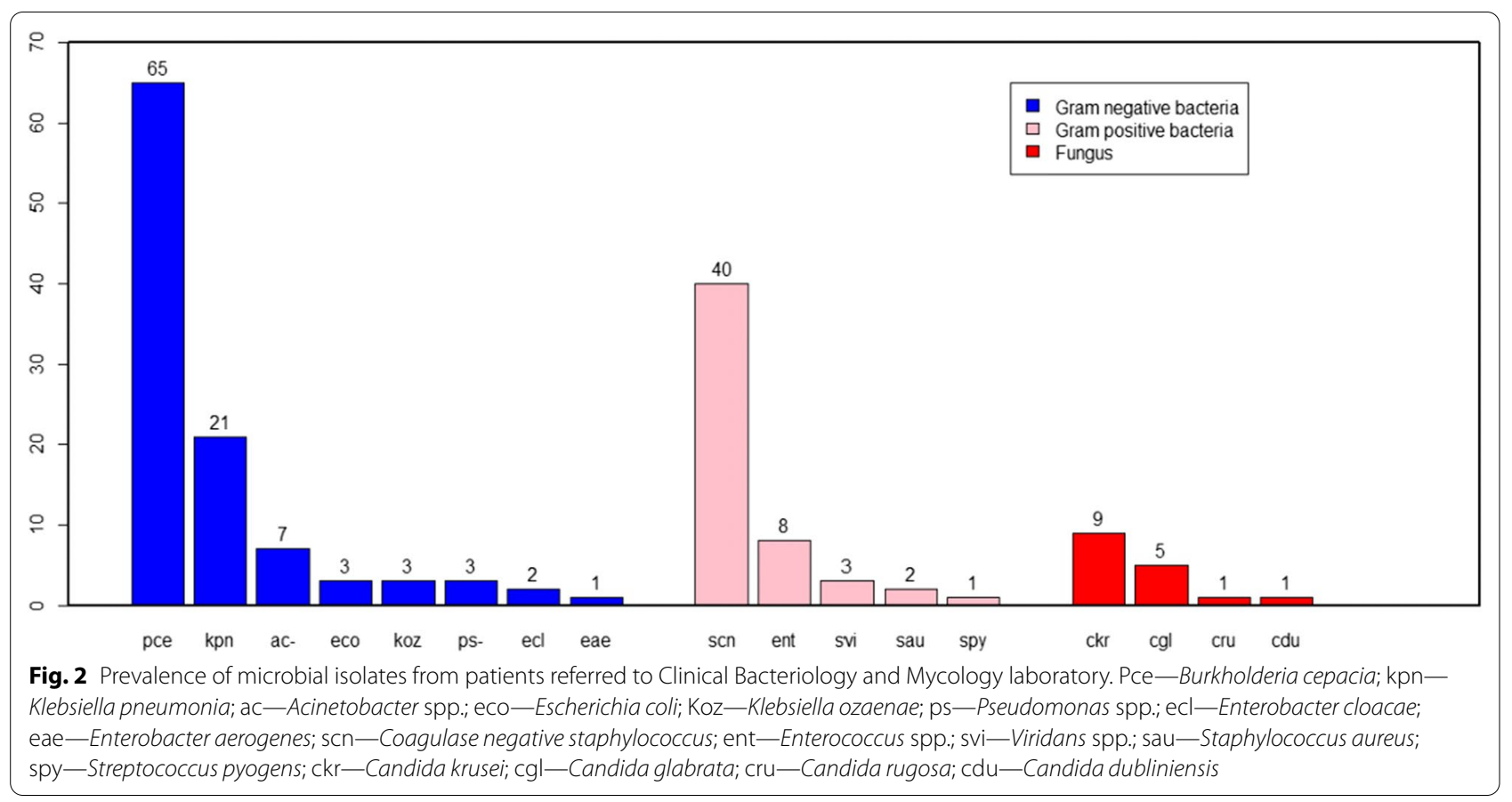

Table 2 Antibiotic resistance patterns of Gram-positive bacteria isolated from blood cultures of patients referred to Clinical Bacteriology and Mycology reference laboratory

\begin{tabular}{|c|c|c|c|c|c|c|c|c|}
\hline \multirow[t]{2}{*}{ Bacterial isolate } & \multicolumn{8}{|c|}{ Antibiotic } \\
\hline & & PEN & OXA & GEN & AMP & VAN & $\mathrm{CHL}$ & CTX \\
\hline $\begin{array}{l}\text { Coagulase negative } \\
\text { staphylococcus }\end{array}$ & $\% R$ & $40(100)$ & $40(89.7)$ & $39(32.5)$ & NT & NT & NT & NT \\
\hline Enteroccus spp. & $\% R$ & $8(75)$ & NT & NT & NT & $8(0)$ & $8(12.5)$ & NT \\
\hline Viridans spp. & $\% R$ & NT & NT & NT & NT & $3(0)$ & NT & $3(33.3)$ \\
\hline S. aureus & $\% R$ & $2(100 \%)$ & $2(0)$ & $2(0)$ & NT & $2(0)$ & NT & NT \\
\hline
\end{tabular}

PEN penicillin; OXA oxacillin; GEN gentamycin; VAN vancomycin; $C H L$ chloramphenicol; $C T X$ cefotaxime; FEP cefepime; $N T$ not tested

Table 3 Antibiotic resistance patterns of Gram-negative bacteria isolated from blood cultures among patients referred to Clinical Bacteriology and Mycology laboratory

\begin{tabular}{|c|c|c|c|c|c|c|c|c|c|c|c|c|}
\hline Bacterial isolate & CAZ & MEM & SXT & AMC & TZP & CRO & FEP & AMK & GEN & TOB & CIP & $\mathrm{CHL}$ \\
\hline B. cepacia & $65(4.62)$ & $65(0)$ & $65(1.53)$ & NT & NT & NT & NT & NT & NT & NT & NT & NT \\
\hline K.pneumoniae & $21(76.2)$ & $21(52.4)$ & $21(85.7)$ & $20(60)$ & 19 (31.6) & $21(81)$ & $21(66.7)$ & $21(0)$ & $20(65)$ & $21(84.2)$ & $6(83.3)$ & $21(47.7)$ \\
\hline Acinetobacter spp. & $7(57.1)$ & $7(71.4)$ & NT & NT & $7(57.2)$ & $7(42.9)$ & $7(42.9)$ & $7(0)$ & $7(71.4)$ & $7(71.4)$ & $6(100)$ & NT \\
\hline E. coli & $3(33.3 \%)$ & $3(0)$ & $3(33.3)$ & $3(33.3)$ & $3(0)$ & $3(66.7)$ & $3(66.7)$ & $3(0)$ & $3(33.3)$ & $2(50)$ & $1(0)$ & $3(0)$ \\
\hline K. ozaenae & $3(66.7)$ & $3(0)$ & $3(66.7)$ & $3(0)$ & $3(0)$ & $3(100)$ & $3(33.3)$ & $3(0)$ & $3(33.3)$ & $3(100)$ & $1(0)$ & $3(33.3)$ \\
\hline Pseudomonas spp. & $3(0)$ & $3(0)$ & NT & NT & $3(0)$ & NT & $3(33.3)$ & $3(0)$ & $3(0)$ & $3(0)$ & $2(0)$ & NT \\
\hline E. cloacae & $2(50)$ & $2(0)$ & $2(100)$ & $2(100)$ & $2(0)$ & $2(0)$ & $2(0)$ & $2(0)$ & $2(100)$ & $2(100)$ & & $2(0)$ \\
\hline E. aerogenes & $1(100)$ & $1(0)$ & $1(100)$ & NT & $1(0)$ & NT & NT & NT & NT & $1(0)$ & $1(0)$ & $1(100)$ \\
\hline
\end{tabular}

CAZ ceftazidime; $M E M$ meropenem; SXT trimethoprim-sulphamethoxazole; $A M C$ amoxicillin-clavulanic acid; TZP piperacillin-tazobactam; $C R O$ ceftraxone; FEP cefipime; AMK amikacin; GEN gentamycin; TOB tobramycin; CIP ciprofloxacin; $C H L$ chloramphenicol; NT not tested 
Table 4 Antifungal resistance patterns of fungal isolates from blood culture of patients referred to Clinical Bacteriology and Mycology laboratory

\begin{tabular}{|c|c|c|c|c|c|c|c|}
\hline Fungal isolate & & AMB & CAS & FCT & FLU & MIF & VOR \\
\hline \multirow[t]{2}{*}{ C. krusei } & $\% \mathrm{R}$ & $9(0)$ & $9(0)$ & $9(22.2)$ & $9(77.8)$ & $9(0)$ & $9(0)$ \\
\hline & $\% \mathrm{~S}$ & $9(100)$ & $9(100)$ & $9(77.8)$ & $9(22.2)$ & $9(100)$ & $9(100)$ \\
\hline \multirow[t]{2}{*}{ C. glabrata } & $\% R$ & $5(40)$ & $5(20)$ & $5(20)$ & $5(80)$ & $5(20)$ & $5(0)$ \\
\hline & $\% \mathrm{~S}$ & $5(60)$ & $5(80)$ & $5(80)$ & $5(20)$ & $5(80)$ & $5(100)$ \\
\hline \multirow[t]{2}{*}{ C.rugosa } & $\% R$ & $1(0)$ & $1(0)$ & $1(100)$ & $1(100)$ & $1(0)$ & $1(0)$ \\
\hline & $\% \mathrm{~S}$ & $1(100)$ & $1(100)$ & $1(0)$ & $1(0)$ & $1(100)$ & $1(100)$ \\
\hline \multirow[t]{2}{*}{ C. dubliniensis } & $\% R$ & $1(0)$ & $1(0)$ & $1(0)$ & $1(100)$ & $1(0)$ & $1(0)$ \\
\hline & $\% \mathrm{~S}$ & $1(100)$ & $1(100)$ & $1(100)$ & $1(0)$ & $1(100)$ & $1(100)$ \\
\hline
\end{tabular}

$A M B$ amphotericin $B ; C A S$ caspofungin; $F C T$ flycytosine; $F L U$ fluconazole; MIF micafungin; VOR voriconazole

Table 5 Multidrug resistance pattern of bacterial isolates from blood culture of patients referred to Clinical bacteriology and Mycology laboratory

\begin{tabular}{|c|c|c|c|c|c|c|c|c|c|}
\hline Bacterial isolate & Ro & R1 & R2 & R3 & R4 & R5 & R6 & R7 & Total MDR \\
\hline K. pneumoneia $(N=21)$ & $1(4.8)$ & $3(14.3)$ & $2(9.5)$ & $2(9.5)$ & $5(23.8)$ & $3(14.3)$ & $0(0)$ & $5(23.8)$ & $15(71.4)$ \\
\hline Acinitobacter spp. $(N=7)$ & $0(0)$ & $0(0)$ & $1(14.3)$ & $3(42.9)$ & $3(42.9)$ & $0(0)$ & $0(0)$ & $0(0)$ & $6(85.7)$ \\
\hline E. $\operatorname{coli}(N=3)$ & $0(0)$ & $1(33.3)$ & $1(33.3)$ & $0(0)$ & $1(33.3)$ & $0(0)$ & $0(0)$ & $0(0)$ & $1(33.3)$ \\
\hline K. ozenae $(N=3)$ & $1(33.3)$ & $0(0)$ & $1(33.3)$ & $0(0)$ & $0(0)$ & $1(33.3)$ & $0(0)$ & $0(0)$ & $1(33.3)$ \\
\hline Pseudomeunos spp. $(N=3)$ & $2(66.7)$ & $1(33.3)$ & $0(0)$ & $0(0)$ & $0(0)$ & $0(0)$ & $0(0)$ & $0(0)$ & $0(0)$ \\
\hline E. cloacae $(N=2)$ & $0(0)$ & $0(0)$ & $0(0)$ & $0(0)$ & $2(100)$ & $0(0)$ & $0(0)$ & $0(0)$ & $2(100)$ \\
\hline E. aeroagens $(N=1)$ & $0(0)$ & $0(0)$ & $0(0)$ & $1(100)$ & $0(0)$ & $0(0)$ & $0(0)$ & $0(0)$ & $1(100)$ \\
\hline Total $(N=40)$ & $4(10)$ & $5(12.5)$ & $5(12.5)$ & $6(15)$ & $11(27.5)$ & $4(10)$ & $0(0)$ & $5(12.5)$ & $26(65)$ \\
\hline
\end{tabular}

$R 1$ resistant for 1 antibiotic, $R 2$ resistant for 2 antibiotics, $R 3$ resistant for 3 antibiotics, $R 4$ resistant for 4 antibiotics, $R 5$ resistant for 5 antibiotics, $R 6$ resistant for 6 antibiotics, $R 7$ resistant for 7 antibiotics

\section{Risk factors for BSIs}

In this study different clinical and socio-demographic factors were observed. The association of prevalence of bacterial infections with independent variables was initially analyzed using a simple regression model. On the basis of cruds odd ratio, the candidate risk factors for the statistical model were sex, age, place of residence, history of admission, sepsis, surgery, empirical therapy, diabetic mellitus, hepatic problem, and utilization of complicated devices at 0.25 level of significant. The candidate risk factors were filtered using multiple logistic regression models. The model suggested sex $(P$-value $=0.007)$, age $(\mathrm{P}$-value $<0.001)$ and utilization of medical devices $(\mathrm{P}$-value $=0.003)$ were significant risk factors for bacterial infections (Table 6).

A multiple regressions model was also done for the predominant bacteria with demographic and clinical conditions. B. cepacia, coagulase negative-staphylococcus and $K$. pneumoniae were the predominant bacteria associated with the independent variable. History of admission ( $\mathrm{P}$-value $=0.006)$ and utilization of medical devices (P-value $<0.001)$ have significant association with B. cepacia. On the other hand, sex $(\mathrm{P}$-value $=0.007)$ has significant association with infection with coagulase negative staphylococcus. $K$. pneumoniae has not significant association with all demographic and clinical conditions.

\section{Discussion}

Blood stream infections are regarded as the most devastating human diseases that lead to complex treatment procedure [16, 25]. The current study mainly illustrated the magnitude of BSIs along with the main risk factors. To our knowledge, this study was the first in addressing B. cepacia as a cause of BSIs in Ethiopia's hospital setting particularly from NICU wards. Furthermore, this study differs from previous research conducted in the same laboratory in BSIs with identification and susceptibility testing for antifungal agents that was not considered a routine testing procedure in many laboratories.

In our study higher prevalence of blood culture confirmed cases [175 (50.58\%)] were observed compared to studies conducted in Port Blair India 14.24\% [26] and Kanpur 22.3\% [27]. The differences may be due to blood specimen volume, time of blood culture taken and epidemiological variation of etiologic agents $[2,4]$. Our finding 
Table 6 Risk factor associated with bacterial cause of blood stream infections among patients referred to Clinical Bacteriology and Mycology reference laboratory

\begin{tabular}{|c|c|c|c|c|c|c|c|c|c|c|}
\hline \multirow[t]{2}{*}{ Characteristics } & \multirow[t]{2}{*}{ Categories } & \multicolumn{3}{|c|}{ Bacterial infection } & \multicolumn{2}{|l|}{ Pce } & \multicolumn{2}{|l|}{ Kpn } & \multicolumn{2}{|l|}{ Sen } \\
\hline & & Number (\%) & AOR & P value & AOR & P value & AOR & P value & AOR & $P$ value \\
\hline \multirow[t]{2}{*}{ Sex $(r e f=$ male $)$} & Female & $74(58.70)$ & 2.05 & 0.007 & 0.76 & 0.424 & 1.72 & 0.241 & 2.68 & 0.007 \\
\hline & Male & $86(39.09)$ & & & & & & & & \\
\hline \multirow[t]{4}{*}{ Age (ref=adult) } & Infant $(<1$ year $)$ & $124(66.67)$ & 5.69 & 0.000 & & 0.984 & 2.29 & 0.184 & 1.98 & 0.125 \\
\hline & Children (1-17) & $5(18.52)$ & 0.66 & 0.456 & 1.11 & 0.999 & 1.06 & 0.959 & 0.67 & 0.627 \\
\hline & Adult (18-64) & $28(23.93)$ & & & & & & & & \\
\hline & Elderly (>64) & $3(18.75)$ & 0.62 & 0.484 & 1.04 & 0.999 & 1.61 & 0.682 & 0.57 & 0.617 \\
\hline \multirow[t]{2}{*}{ Place of residence (ref $=$ rural) } & Urban & $71(52.59)$ & 0.82 & 0.458 & 0.80 & 0.51 & 0.57 & 0.594 & 0.71 & 0.359 \\
\hline & Rural & $89(42.18)$ & & & & & & & & \\
\hline Surgery $(r e f=$ no) & Yes & $25(35.71)$ & 0.86 & 0.465 & 1.59 & 0.371 & 1.64 & 0.41 & 0.71 & 0.538 \\
\hline Ever admitted $(r e f=n o)$ & Yes & $46(36.8)$ & 0.82 & 0.652 & 0.30 & 0.006 & 0.75 & 0.59 & 2.64 & 0.012 \\
\hline SEPSIS (ref=no) & Yes & $93(55.03)$ & 0.97 & 0.899 & 0.70 & 0.304 & 1.07 & 0.888 & 0.94 & 0.878 \\
\hline $\begin{array}{l}\text { Utilization of complicated } \\
\text { devices (ref }=\text { no) }\end{array}$ & Yes & $99(52.66)$ & 2.24 & 0.003 & 3.52 & 0.000 & 1.39 & 0.508 & 0.69 & 0.329 \\
\hline
\end{tabular}

Pce-Burkolderia cepacia; Scn-Coagulase negative staphylococcus; Kpn-Klebsiella pneumoniae

might be higher due to the emerging of new nosocomial pathogen B. cepacia.

The percentage of bacterial isolation in this study was 159 (45.95\%), which was approximately similar to the previous study conducted in Ethiopia [164 (32.8\%)] [12]. In contrast to the above finding, different studies conducted in European, African countries, and Ethiopia reported a lower isolation rate of bacterial infections [13, $28-34]$. The possible reason for this variation may be the predominance of $B$. cepacia detection that may increase the positivity rate in the present study.

The prevalence of bacterial blood stream infections in relation to age groups illustrated that blood culture positivity was higher among infants (77.36\%) than other age groups. This finding was in line with the study performed in rural tertiary care hospital in India [25], Gonder university hospital [34] and Nigeria [13]. The predominance of bacterial BSIs among infants may be due to immaturity of the immune system which contributes to ease of susceptibility to infections [35].

The predominant pathogens causing BSIs in our study were found to be Gram-Negative bacteria, which is similar to other studies in Rim Hospital [32], Nigeria [13], Jimma [36], Addis Ababa [37] and Tikur Anbessa [31]. The higher percentage of Gram-negative bacteria in this study most likely due to a higher number of $B$. cepacia which is emerging as outbreak NICU wards.

Bacterial isolation varies among country to country. B. cepacia, Coagulase-negative staphylococcus, K. pneumoneia, E. coli, Acinetobacter spp. and Pseudomonas spp. were the most commonly isolated bacteria that caused bloodstream infections in this study, which is more or less similar to previous studies [13, 28, 38-40]. Among the Gram-negative bacteria B. cepacia was found as the highest percentage. The predominancy of this bacteria may be due to about $77.36 \%$ of patients in the current study was infants from NICU and all of these isolates were identified from these patients. B. cepacia is an important nosocomial pathogen that causes outbreak in hospital settings especially in neonatal units. It is also capable of adhering to various medical instruments and colonizing solutions taken as an injection for medication that may be capable of transmitting to neonates [41].

Like many other studies [16, 19, 30, 35, 42-45], Coagulase-negative staphylococcus was the predominant Gram-positive organism in our study as a causative agent of BSIs. The high prevalence of Coagulase-negative staphylococcus could be the higher number of blood samples in our study were from neonatal intensive care unit which was frequently associated with the utilization of intravascular devices that serve as portals of entry to the bloodstream [46].

Fungemia has been confirmed in $9(9.14 \%)$ cases. The result was consistent with a study conducted in New York City 9.8\% [47], Saudi Arabia 9.5\% [16] and India 9.2\% [48]. All fungemia infections in this study were due to non-C. albicans species which is in agreement with other studies [27, 43, 49]. But our finding was different from studies conducted in Turkey [50] and India [14] which found $C$. albicans as a cause of BSIs. The major risk factors leading to fungal infection in our study were prolonged hospital stay and previous broadspectrum antimicrobial treatment [14]. 
Klebsiella spp. showed high resistance to folate pathway inhibitors, floroqunioles, aminoglycoside, and ßeta lactamases inhibitors. Third-generation and fourth-generation cephalosporins also exhibited very weak activity against this organism. A similar finding was noted among studies carried out in Nepal [35], Gonder university hospital [34] and India [51].

Among non-fermenter, Acinetobacter spp. showed extremely resistance to fluoroquinolones and carbnem drugs. They were also moderately resistance to other antibiotics such as aminoglycoside, third and fourth generation cephalosporin, and aminoglycoside and ßeta lactam inhibitors. This finding was consistent with the study done in Iran which showed that Acinetobacter spp. was the most resistant bacteria against most antibiotics tested [52]. The main reason for this problem may be inappropriate use of antibiotics and lack of standard antibiotic policy in the hospital. Amikiacin was the most effective antibiotic against Gram-negative agents that is comparable in studies performed in Asian and Arab countries [49, 52-54].

In our study, a higher degree of resistance was observed in penicillin among Gram-positive organisms which showed conformity with studies done in Jimma [33] and Afghanistan [44]. All Gram-positive bacteria were sensitive to vancomycin that is similar to other studies $[19,43$, $51,53,55]$. However, different from the study in India, vancomycin resistance and intermediate $S$. aureus were observed [48]. The difference may be the number of isolates that were identified. MRSA was observed in the predominant organism Coagulase-negative staphylococcus which similar to study in tertiary care hospital in India [51] and Nepal [35].

In our study, the highest resistance rate of azole drugs observed in fluconazole in C. krusei showed similarity in studies conducted in India [38] and Turkey [50]. However, Study in Qatar showed most Candida spp., were sensitive to fluconazole, which is different from our study [49]. There is no resistance against voriconazole in all candida isolates which was in line with study done in Turkey [50].

Many factors contribute to the prevalence of BSIs. In the current study Sex, Age, and utilization of complicated devices were independent risk factors for BSIs caused by bacterial infection. This finding agrees with a study conducted in Gonder university hospital that has a significant association between age and BSIs [34].

\section{Conclusions}

In this study, the frequency of Gram-negative bacteria that causes BSIs was higher compared to Grampositive bacterial and fungal isolates. Fungemia due to non-C. albicans was common fungal causative agent.
Sex, age, and utilization of complicated devices were found to be the main risk factor that causes BSIs associated with bacterial infections. Both Gram-positive and Gram-negative bacteria showed an increasing level of resistance to most antibiotics that have been used for empirical therapy. This highlights continuing investigation of etiologic agents and assessment of infection control is necessary to reduce the disease impact. In addition, it is important to revise treatment guidelines based on the predominant pathogen and resistance patterns at the health facility level.

\section{Limitation of the study}

All specimens during the study period were collected from Addis Ababa health care facilities that could not represent the national data of Ethiopia. There was no information whether the cases were communityacquired or healthcare-acquired infections, even though the majority of the isolates were identified from NICU.

\section{Acknowledgements}

We would like to thank Ethiopian Public Health Institute, Clinical Bacteriology and Mycology Reference Laboratory for their cooperation to use the laboratory facilities.

\section{Authors' contributions}

EA: Study conception and design, Acquisition of data, Drafting of manuscript, Critical revision and approval of the final version. DS, AA, TL and AB: Critical Acquisition of data, revision and approval of the final version. ZT: Acquisition of data and statistical analysis. All authors read and approved the final manuscript.

\section{Funding}

Not applicable.

\section{Availability of data and materials}

The datasets used and/or analyzed during the current study are available from the corresponding author on reasonable request.

\section{Declarations}

Ethics approval and consent to participate

Approval was obtained from the department of medical laboratory sciences, Addis Ababa University. Data collection was started after written informed consent/ascent was obtained from the study participants. Informed consent was also obtained from parent/guardian of study participants below 16 years of age. Addis Ababa University had ethics committee to approve the study on humans.

\section{Consent for publication}

Not applicable.

\section{Competing interests}

The authors declare that they have no competing interests.

\section{Author details}

${ }^{1}$ National Clinical Bacteriology and Mycology Case Team, Ethiopian Public Health Institute, Addis Ababa, Ethiopia. ${ }^{2}$ Department of Medical Laboratory Science, College of Health Science, Addis Ababa University, Addis Ababa, Ethiopia. ${ }^{3}$ Departement of Statistics, College of Natural and computational science, Addis Ababa University, Addis Ababa, Ethiopia. 
Received: 16 June 2021 Accepted: 23 November 2021

Published online: 29 November 2021

\section{References}

1. Franco-Paredes C. Core concepts in clinical infectious diseases (CCCID). London: Academic Press; 2016.

2. Weinstein MP. Current blood culture methods and systems: clinical concepts, technology, and interpretation of results. Clin Infect Dis. 1996;23(1):40-6.

3. World Health Organization. Global report on the epidemiology and burden of sepsis: current evidence, identifying gaps and future directions. Geneva: World Health Organization; 2020.

4. Reimer LG, Wilson ML, Weinstein MP. Update on detection of bacteremia and fungemia. Clin Microbiol Rev. 1997;10(3):444-65.

5. Pfaller MA, Jones RN, Doern GV, Kugler K, Group SP. Bacterial pathogens isolated from patients with bloodstream infection: frequencies of occurrence and antimicrobial susceptibility patterns from the SENTRY antimicrobial surveillance program (United States and Canada, 1997). Antimicrob Agents Chemother. 1998;42(7):1762-70.

6. Kamga H, Njunda A, Nde P, Assob J, Nsagha D, Weledji P. Prevalence of septicaemia and antibiotic sensitivity pattern of bacterial isolates at the University Teaching Hospital, Yaoundé, Cameroon. Afr J Clin Exp Microbiol. 2011. https://doi.org/10.4314/ajcem.v12i1.61037.

7. Thomas SR, Sajeena Jose C, Damodaran D, Benny E, Jha A, Chandur VK, et al. A tertiary care hospital based study on antimicrobial sensitivity pattern among septic patients. Int J Cur Res Rev. 2019;11(10):7.

8. Tille PM. Bailey \& Scott's diagnostic microbiology. fourteenth. Amsterdam: Elsevier; 2017

9. Vandepitte J, Verhaegen J, Engbaek K, Rohner P, Piot P, Heuck C, et al. Basic laboratory procedures in clinical bacteriology. Geneva: World Health Organization; 2003.

10. Laupland KB, Church DL. Population-based epidemiology and microbiology of community-onset bloodstream infections. Clin Microbiol Rev. 2014;27(4):647-64.

11. Vlieghe E, Phoba M, Tamfun JM, Jacobs J. Antibiotic resistance among bacterial pathogens in Central Africa: a review of the published literature between 1955 and 2008. Int J Antimicrob Agents. 2009;34(4):295-303.

12. Kitila K, Taddese B, Hailu T, Sori L, Geleto S. Assessment of bacterial profile and antimicrobial resistance pattern of bacterial isolates from blood culture in Addis Ababa Regional Laboratory, Addis Ababa, Ethiopia. Clin Microbiol. 2018;7(312):2

13. Nwadioha I, Odimayo MS, Omotayo J, Taiwo AO, Olabiyi E. A retrospective cross sectional study of blood culture results in a tertiary hospital, Ekiti, Nigeria. Open J Med Microbiol. 2015;5(04):202.

14. Siddiqui N, Kirmani S, Khan F, Kaushal N, Shukla I, Khan HM, et al. Prevalence and risk factors of Candida blood stream infections in a tertiary care hospital. Int J Curr Microbiol Appl Sci. 2015;1:157-62.

15. Timsit J-F, Soubirou J-F, Voiriot G, Chemam S, Neuville M, Mourvillier $B$, et al. Treatment of bloodstream infections in ICUs. BMC Infect Dis. 2014;14(1):489.

16. Elbashier AM, Malik AG, Khot AP. Blood stream infections: micro-organisms, risk factors and mortality rate in Qatif Central Hospital. Ann Saudi Med. 1998;18(2):176-80.

17. Alemnew B, Biazin H, Demis A, Abate Reta M. Bacterial profile among patients with suspected bloodstream infections in Ethiopia: a systematic review and meta-analysis. Int J Microbiol. 2020. https://doi.org/10.1155/ 2020/8853053.

18. World Health Organization. Antimicrobial resistance global report on surveillance: 2014 summary. Geneva: World Health Organization; 2014.

19. Teshale AM, Abera NA, Ibrahim RA, Dinku SF, Negeri AA, Oda MA, et al. Prevalence and antimicrobial susceptibility of bacterial isolates from blood samples referred to National Reference Laboratory, Ethiopia. Ethiop J Public Health Nutr. 2020;2(1):20-4.

20. CLSI. Performance standards for antimicrobial susceptibility testing. Vol. 31 th ed., CLSI supplement M100S. Wayne: Clinical and Laboratory Standards Institute; 2021

21. Bauer A, Kirby W, Sherris JC, Turck M. Antibiotic susceptibility testing by a standardized single disk method. Am J Clin Pathol. 1966:45(4_ts):493-6.
22. Page B, Klompas M, Chan C, Filbin MR, Dutta S, McEvoy DS, et al. Surveillance for healthcare-associated infections: hospital-onset adult sepsis events versus current reportable conditions. Clin Infect Dis. 2021. https:// doi.org/10.1093/cid/ciab217.

23. Wayne P. Method for antifungal disk diffusion susceptibility testing of yeasts. CLSI m44-a. 2004.

24. Magiorakos A-P, Srinivasan A, Carey R, Carmeli Y, Falagas M, Giske C, et al. Multidrug-resistant, extensively drug-resistant and pandrug-resistant bacteria: an international expert proposal for interim standard definitions for acquired resistance. Clin Microbiol Infect. 2012;18(3):268-81.

25. Sweta O, Sanjay JM, Kikani MK, Sunil GO. Bacteriological profile and antibiogram of blood culture isolates from patients of rural tertiary care hospital. Indian J Microbiol Mycol. 2016;4(3):1-7.

26. Banik A, Bhat SH, Kumar A, Palit A, Snehaa K. Bloodstream infections and trends of antimicrobial sensitivity patterns at Port Blair. J Lab Physicians. 2018;10(3):332.

27. Pal N, Sujatha R. Antimicrobial resistant pattern of blood culture isolates, among septicaemia suspected patients. Natl J Lab Med. 2016;5(1):17-21.

28. Onken A, Said AK, Jørstad M, Jenum PA, Blomberg B. Prevalence and antimicrobial resistance of microbes causing bloodstream infections in Unguja, Zanzibar. PLoS ONE. 2015;10(12):e0145632.

29. Wasihun AG, Wlekidan LN, Gebremariam SA, Dejene TA, Welderufael AL, Haile TD, et al. Bacteriological profile and antimicrobial susceptibility patterns of blood culture isolates among febrile patients in Mekelle Hospital, Northern Ethiopia. Springerplus. 2015;4(1):314.

30. Abebaw A, Tesera H, Belachew T, Mihiretie GD. The bacterial profile and antibiotic susceptibility pattern among patients with suspected bloodstream infections, Gondar, north-west Ethiopia. Pathol Lab Med Int. 2018;10:1.

31. Bitew A. Multi-drug resistance profile of bacteria isolated from blood stream infection at Tikur Anbessa Specialized Hospital, Addis Ababa, Ethiopia. EC Microbiol. 2018;14:119-26.

32. Devi AV, Sahoo B, Damrolien S, Praveen S, Lungran P, Devi KM. A study on the bacterial profile of bloodstream infections in Rims Hospital. J Dent Med Sci. 2015;14:18-23.

33. Zenebe T, Kannan S, Yilma D, Beyene G. Invasive bacterial pathogens and their antibiotic susceptibility patterns in Jimma University specialized hospital, Jimma, Southwest Ethiopia. Ethiop J Health Sci. 2011;21(1):1-8.

34. Dagnew M, Yismaw G, Gizachew M, Gadisa A, Abebe T, Tadesse T, et al. Bacterial profile and antimicrobial susceptibility pattern in septicemia suspected patients attending Gondar University Hospital, Northwest Ethiopia. BMC Res Notes. 2013:6(1):283.

35. Pokhrel B, Koirala T, Shah G, Joshi S, Baral P. Bacteriological profile and antibiotic susceptibility of neonatal sepsis in neonatal intensive care unit of a tertiary hospital in Nepal. BMC Pediatr. 2018;18(1):208.

36. Kumalo A, Kassa T, Mariam ZS, Daka D, Tadesse AH. Bacterial profile of adult sepsis and their antimicrobial susceptibility pattern at Jimma University specialized hospital, south West Ethiopia. Health Sci J. 2016;10(2):1

37. Negussie A, Mulugeta G, Bedru A, Ali I, Shimeles D, Lema T, et al. Bacteriological profile and antimicrobial susceptibility pattern of blood culture isolates among septicemia suspected children in selected hospitals Addis Ababa, Ethiopia. Int J Biol Med Res. 2015;6(1):4709.

38. Gupta S, Kashyap B. Bacteriological profile and antibiogram of blood culture isolates from a tertiary care hospital of North India. Trop J Med Res. 2016;19(2):94.

39. Seni J, Mwakyoma A, Mashuda F, Marando R, Ahmed M, DeVinney R, et al. Deciphering risk factors for blood stream infections, bacteria species and antimicrobial resistance profiles among children under five years of age in North-Western Tanzania: a multicentre study in a cascade of referral health care system. BMC Pediatr. 2019;19(1):32.

40. Babay HA. Bacterial isolates from fatal cases of bloodstream infections at a university hospital in Central, Saudi Arabia. Saudi Med J. 2007:28(2):231.

41. Schmitt C, Maciel A, Baraldi M, Simonetti M, Cantarelli M, Turcato G, et al. Bloodstream infection outbreak caused by Burkholderia cepacia complex: the role of genetic sequencing in the investigation. Antimicrob Resist Infect Control. 2015;4(S1):P228.

42. Mpinda-Joseph P, Anand Paramadhas BD, Reyes G, Maruatona MB, Chise M, Monokwane-Thupiso BB, et al. Healthcare-associated infections including neonatal bloodstream infections in a leading tertiary hospital in Botswana. Hosp Pract. 2019. https://doi.org/10.1080/21548331.2019. 1650608. 
43. Patel KK, Patel S, Sinha D. Bacteriological profile and antibiotic resistance pattern in blood stream infection in critical care units of a tertiary care hospital in central India. Blood. 2016;50:1.

44. Tariq TM. Bacteriologic profile and antibiogram of blood culture isolates from a children's hospital in Kabul. J Coll Physicians Surg Pak. 2014;24(6):396-9.

45. Karlowsky JA, Jones ME, Draghi DC, Thornsberry C, Sahm DF, Volturo GA Prevalence and antimicrobial susceptibilities of bacteria isolated from blood cultures of hospitalized patients in the United States in 2002. Ann Clin Microbiol Antimicrob. 2004;3(1):7.

46. Karunakaran R, Raja NS, Ng KP, Navaratnam P. Etiology of blood culture isolates among patients in a multidisciplinary teaching hospital in Kuala Lumpur. J Microbiol Immunol Infect. 2007:40(5):432.

47. Orsini J, Mainardi C, Muzylo E, Karki N, Cohen N, Sakoulas G. Microbiological profile of organisms causing bloodstream infection in critically ill patients. J Clin Med Res. 2012;4(6):371.

48. Gohel K, Jojera A, Soni S, Gang S, Sabnis R, Desai M. Bacteriological profile and drug resistance patterns of blood culture isolates in a tertiary care nephrourology teaching institute. BioMed Res Int. 2014. https://doi.org/ 10.1155/2014/153747.

49. Ahmed A, Lutfi S, Al-Hail M, Al-Saadi M. Antibiotic susceptibility patterns of microbial isolates from blood culture in the neonatal intensive care unit of Hamad Medical Corporation (HMC), Doha, Qatar. Asian J Pharm Clin Res. 2013;6(Suppl 2):191-5.

50. Aydin F, Bayramoglu G, Guler NC, Kaklikkaya N, Tosun I. Bloodstream yeast infections in a university hospital in Northeast Turkey: a 4-year survey. Med Mycol. 2011;49(3):316-9.

51. Rajeevan S, Ahmad SM, Jasmin P. Study of prevalence and antimicrobial susceptibility pattern in blood isolates from a tertiary care hospital in North Kerala, India. Int J Curr Microbiol Appl Sci. 2014;3(4):655-62.

52. Nobandegani AS, Motamedifar M. Antibiotic sensitivity profile of the bacterial isolates from the blood samples of the patients in different wards of a major referral hospital, Shiraz, Iran 2015-2016:30-36.

53. Fayyaz M, Mirza IA, Ikram A, Hussain A, Ghafoor T, Shujat U. Pathogens causing blood stream infections and their drug susceptibility profile in immunocompromised patients. J Coll Physicians Surg Pak. 2013;23(12):848-51.

54. Mehta M, Dutta P, Gupta V. Antimicrobial susceptibility pattern of blood isolates from a teaching hospital in North India. Jpn J Infect Dis. 2005:58(3): 174

55. Gandhi V, Patel M. Prevalence of Candida species and its antifungal susceptibility isolated from blood culture at tertiary care hospital, Ahmedabad, India. Int J Curr Microbiol Appl Sci. 2017;6:884-92.

\section{Publisher's Note}

Springer Nature remains neutral with regard to jurisdictional claims in published maps and institutional affiliations.

Ready to submit your research? Choose BMC and benefit from:

- fast, convenient online submission

- thorough peer review by experienced researchers in your field

- rapid publication on acceptance

- support for research data, including large and complex data types

- gold Open Access which fosters wider collaboration and increased citations

- maximum visibility for your research: over $100 \mathrm{M}$ website views per year

At BMC, research is always in progress.

Learn more biomedcentral.com/submissions 